\title{
The Importance of Culture in ERP Adoption - A Case Study Analysis
}

\author{
By Dimitra Skoumpopoulou* \\ Catherine Moss ${ }^{\dagger}$
}

\begin{abstract}
The purpose of this study is to explore the importance of culture in (Enterprise Resource Planning) ERP adoption and to understand why ERP projects commonly fail. This study identifies culture as an underlying issue for such failures. The researchers use the Handy model of culture as a self-diagnosis tool for culture and organisational change that can be utilised as a facilitator for culture and ERP adoption success. This study uses a case study analysis as a qualitative approach to identify a diverse array of perceptions across hierarchal structures within a selected organisation who has recently adopted a cultural change program prior to adoption. Our study found that a cultural change led to enhanced communication, leadership and a sense of coherency across the whole organisation. We argue that if the organisation continues to improve its culture then successful ERP adoption could become a reality rather than an ideal.
\end{abstract}

Keywords: Culture, Enterprise Resource Planning, Case Study.

\section{Introduction}

Globalisation as an international integration phenomenon presents continuous pressures for organisations to sustain competitive advantage (Awuah and Amal 2011). The challenging environment of evolving customer preferences, diversifycation of products within new markets, and the threat of competition from reduced barriers to entry have increasingly demanded that organisations must act and evolve to survive (Kumar et al. 2010). To accomplish this objective, companies have taken a collaborative approach to upgrading their capabilities and internally developing their business processes through the adoption of enterprise resource planning (ERP) (Umble et al. 2003). ERP is a highly complex information system (IS) that provides a unified view of internal business activities as a means of communicating and cooperating across interdepartmental units (Umble et al. 2003). ERP therefore enables companies to achieve their objectives through enhanced cooperation amongst stakeholders as well as providing a cost reduction strategy that sustains competitive advantage (Kumar et al. 2010).

However, the adoption process unfortunately exposes a sense of uncertainty and vulnerability held by management due to the lack of tangibility of the unquantifiable benefits during adoption stages (Ram et al. 2014). Thus, the

${ }^{*}$ Senior Lecturer in Information Management, Faculty of Business and Law, Northumbria University, UK.

${ }^{\dagger}$ Alumni of Newcastle Business School, Nook Farm House, Humblescough Lane, UK. 
unfeasibility of weighing up the realised benefits over total costing element could interfere with a successful adoption that enhances value towards the imperative stakeholders.

Academics have recognised and identified a measure for success called Critical Success Factors (CSFs) in order to ensure that the correlation between adoption and success is effectively managed and realised in application. However, this increment has failed in delivering its theoretical promises within a legitimate, realistic and applied context (Tallon et al. 2000, Kappos and Rivard 2008).

Therefore the main objectives of this study are:

- To explore the theory related to organisational culture in understanding its impact in ERP adoption.

- To discover employees' perceptions in ERP adoption and to further understand the complexities that the organisation under scrutiny faced in adoption.

Therefore our paper is divided in four parts. The next part critically reviews the literature while part two discusses the methodology used for this research. Part three presents the findings and discussion while part four summarises the main conclusions of our research.

\section{Literature Review}

The overall purpose of ERP is to provide a unified view of the business that encompasses transactional activities throughout all functions that act in management's favour in delivering faster and enhanced business solutions in decision making (Soh et al. 2000, Nah et al. 2001, Umble et al. 2003). In 2013, the ERP software market represented a total market value of $\$ 25.4 \mathrm{~B}$; a $3.8 \%$ increase from the prior year (Columbus 2014). Forbes newspaper analyst and ERP and cloud computing expert Louis Columbus - published his review of the Gartner Group's annual 2013 results, which reported lead market share dominance by SAP followed by Oracle, Sage and Infor.

ERP's function as a piece of technological infrastructure providing substantial benefit and strategic value has been questioned by academics due to management's failure of justifying their expected benefits at adoption stage. According to Ram et al. (2014), the analysis of weighing up the potential benefits over the total costing element has been a difficult measure to quantify due to the organisational change associated in adoption (Willcocks and Lacity 1998). Similarly, it is very difficult to demonstrate a positive connection between ERP adoption and organisational performance (Buonanno et al. 2005, Law and Ngai 2007, Kallunki et al. 2011) while Beheshti's (2010) study argues that this is because of the intangible benefits that encompass ERP adoptions. This part starts by exploring relevant Critical Success Factors related to ERP adoption. Also, we discuss the concept of culture in organisations and the extent to which culture is important 
while adopting ERP systems. Finally this part discusses the theoretical basis of our research the Handy model of culture.

\section{CSF and How They Impact an ERP Adoption}

CSFs were first introduced within a management school in 1979 by John Rockart who tried to categorise information required by management that could be defined and utilised within managerial decisions and organisations effectively (Rockart 1979). He emphasised that organisational planning should focus on the success factor element by which three to six possible success factors should be incorporated in decision making by delivering the necessary competencies and errands that reinforce organisational success.

Research has already identified CSFs for organisational success in relation to ERP adoption (Nah et al. 2001, Umble et al. 2003, Françoise et al. 2009, Ram et al. 2013, Ram et al. 2014). According to Shaul and Tauber (2013), across 341 articles the number CSFs identified by authors was up to 94 factors. Within individual studies, academics proposed up to 20 factors alone to coincide in organisational planning where reinforcement would determine implementation success. However, according to Chang (2004), $67 \%$ of organisations fail to commit to the organisational initiatives proposed by managers. Similarly Kappos and Rivard (2008) and Tallon et al. (2000) criticise on ground of impracticality, but argue that one straightforward factor can impact the implementation stage with greater affect than number of selected factors. Hence, successful adoption is made unattainable when complex organisations try to control multiple and irrelevant CSF variables within ERP adoption. The top three CSFs identified to coincide in planning for an enhanced probability of successful adoption are top management support, strategic focus and employee training (Davenport 2000, Dezdar and Ainin 2011, Pishdad and Haider 2013, Maclennan and Belle 2014).

Though "failure" is relatively a subjective term with different possible interpretations throughout the adoption stage, the researchers had identified a reoccurring theme within literature as to why ERP project fails. According to Chang (2004), 90\% of implementations do not meet the deadline or budget proposed by management, $67 \%$ fail to implement the organisations initiatives and commonly, $40 \%$ of large-scale ERP projects fail. In relation to adoption, Kumar et al. (2010) specified that the planning stages are vulnerable to risk where errors within the decision making process trigger various barriers within upcoming stages of the project. Chen et al. (2009) argued that IT management set poorly defined objectives and have a poor planning strategy that gives a one-dimensional view of adoption- failing to congregate organisational acceptance from the array of stakeholders within the organisation (Chen et al. 2009).

Similarly, Umble et al. (2003) reviewed a survey of IT managers published by Information week relating to ERP project failure. $77 \%$ had stated that project failure was due to poor planning and management, $75 \%$ proposed it was due to the lack of strategic direction and $73 \%$ attributed failure to a lack of managerial support. Kuruppuarachchi et al. (2002) indicated that IT projects were subject to failure due to poor communications between IT experts and 
their stakeholders whereas Aloini et al. (2012) stated that the failure rate was high due to managers' lack of consideration to manage the necessary risks to make key business decisions (Wei et al. 2005). As articulated, Kumar's et al. (2010) paper specifies the key risks associated in adoption.

Whilst the implications and the practicality for error is high risk, this study recognises that the fundamental issues identified by researchers stem and originate from the basis of human and behavioural thinking. This raises the issue of whether CSF is a useful tool for success given how the factor is applied and adopted due to its variance in delivery. Thus, the behavioural element of adopting CSFs fails in its practicality. As Eaton and Kilby (2015) argue, whatever initiatives or factors management have embedded to counteract ERP failure and comprise a successful adoption will be offset by the power of culture if the change element conflicts with the organisations values, beliefs and behavioural norms. Thus, the next part of this paper will look at culture and its relation to ERP adoption to help close the gap between the "what" and "how" aspects in ERP failure (Chen et al. 2009).

\section{Culture in Organisations}

Academics have defined culture within different contexts where broadly no accepted definition exists (Hill et al. 2012). Hofstede (1998) distinguished culture through behavioural norms that differentiate and categorise individuals within a social group of similar personalities. From an organisational perspective, Schein (1993: 9) defined culture as "a pattern of basic assumptions...by a given group as it learns to cope with its problems of external adaption and internal integration- that has worked well enough to be considered valuable and therefore, to be taught to new members as the correct way to perceive, think and feel in relation to those problems". Thus, Schein defines culture within a motivational stance that is developed through the history of behavioural norms; utilised as a custom of coping with pressures of the business that ensues competitive advantage. However, these traditional views of culture have been criticised as holding an old-fashioned and unrealistic view of the term (Avison and Myers 1995, Myers and Tan 2002).

Hofstede (1998) conducted a case study analysis within a large Danish insurance business which identified three distinct sub-cultures over hierarchal positions. In relation to Martin's (1992) model, this research suggested that a 'differentationist' perception was recognised: a mixture of the two extreme acuities and that sub-cultures exist within organisations. Concordantly, Harris and Ogbonna (1999) discovered that top management typically adopted 'integrationist'; line managers adopted 'differentationist' whereas subordinates adopted a 'fragmentationist' outlook.

The universal presence of subcultures in business suggests the threat of failed consensus vision amongst the organisations that inflict its logic of conflict and misinterpretation amongst peers. Therefore, in relation to ERP adoption, the failure of communicated vision and acceptance from stakeholders holds risk of project failure (Kuruppuarachchi et al. 2002, Kumar et al. 2010, Aloini et al. 2012). 


\section{Importance of Culture in ERP Adoptions}

Human interaction on projects are subject to risk and seemingly, the unpinning literature between human behaviour and ERP has indicated that the purpose for failure, is in fact, a cultural one (Soh et al. 2000, Davison 2002, Rabaai 2009).

It is argued that for organisations to realise the ample benefits of ERP packages, companies must utilise the full functionality that the ERP software provides in delivering its value (Boudreau 2002). However, because ERP systems impose its own logic of a company's strategy, culture and processes (Davenport 1998), this demands a great deal of organisational change (Kwahk 2006). As organisational change has the power of altering company objectives, structure and working practise, it has been proposed that IT systems hold this power as an enabler to change (Kwahk 2006). However, according to Soh et al. (2000), the process of ERP adoption has a disruptive nature with the possibility of failure due to resistance to imposed change and a strategy which may conflict with existing cultural identities (Eaton and Kilby 2015).

Nonetheless, Rajapakse (2012) proposed that in the avoidance of ERP's reputation of a provoking disruptive mechanism, organisations can utilise ERP projects in order to gain success by eliminating cultural issues in adoption by strategically transforming organisational cultural change within the process. Though the study was limited by being focussed on Asian cultures, it nevertheless recognises a gap in understanding cultural transformation through ERP adoption. Seemingly though not directly related to ERP, Eaton and Kilby's (2015) research offers a generic insight into how companies' fail to recognise self-diagnosed issues of cultural identity and how cultural inefficiencies are currently restricting capability of reaching company objectives. Thus, to combat the uncertainty over self-diagnosis of managing such cultures, this study will explore a theoretical framework that omits such qualms.

The numerous contenders of stakeholders involved within ERP implementation hold a diverse range of organisational perspectives, objectives, and interest towards the project (Fowler and Gilfillan 2003, Somers et al. 2004). However, as diversity is sought to be managed within organisations, a highly integrational project such as implementing an ERP system tests these stakeholders' capabilities. Stakeholder diversity produces a conflict of interest between cultures and interests, the failure and resistance in obtaining organisational objectives and finally the lack of IT knowledge to manage the functionality of the systems (Barki and Hartwick's 2001, Somers et al. 2004, Tai et al. 2014). Harrison and Klein (2007) identify that various stakeholders subconsciously form group identities from interests of equality and divide ERP project teams. Therefore, various stakeholder perceptions of ERP adoption and implementation cannot be completely controlled for, where the practicality of a sub-cultural organisation imposes its risk for ERP failure. However according to Hill et al. (2012), a diverse stakeholder group which encompasses a 'differentionist' perspective holds substantial benefits due to its deterrence away from the 'groupthink' phenomenon that stands as a custom to organisational value (Rajapakse 2012). In reference to 
ERP related context, Tai et al. (2014) identified that if the element of social identity is applied; that is the inclusion between stakeholder diversity groups within the adoption process, acceptance and proactive engagement will occur. Thus, this study uses a theory which captures the link between stakeholder diversity and ERP acceptance for success and it is discussed below.

\section{Theoretical Model}

Handy's model (Handy 1976) of the four types of culture proposes a simple and flexible convention of identifying different types of culture but offers a critical appreciation for diverse cultures that managers can use to self-diagnose their organisations identity and harness a favourable culture in organisational change.

- The 'Role Culture' symbolises a bureaucratic or functional structure of tight management control. An advantage to those individuals who seek consistency in job task but hindrance to individuals who seek creativity in work. A slow progress organisation where change is infrequently viable.

- The 'Task Culture' is solely on accomplishing the organisational objective through working in teams. A 'task culture' holds its advantages of its philosophy for change, adaption and individual freedom. However, as a disadvantage, the structure weakens where resources are limited thus, control will be taken over by management- resulting in a low morale in teams.

- The 'Power Culture' tends to be an organisation where one powerful individual or a small group of individuals have complete control. Thus, the powerful individual influences how the organisation should be operated which provokes its advantages of pursuing successful 'end results' but holds its disadvantages of employee estrangement.

- The 'People Culture' has employees as the main focus where it exists to serve its members. Individuals follow individual objectives and get on with their roles without interference which, as an advantage encourages creativity and empowerment but holds its disadvantage of lack cohesiveness and control.

This model draws relevance to this research as it captures and identifies cultures by behavioural norms and advises a self-diagnosis of cultural identity that recommends on improvement needs of ones cultures that managers can utilise as a catalyst for success. Thus, this model will assist in understanding the complexities that the organisation under scrutiny faced in adoption as well as understanding the impact of a change in culture prior to adoption and ERP success-coinciding with Rajapakse's (2012) study of transforming organisational cultural change in the avoidance of ERP failure.

The proposed theoretical framework has increased relevance and advantages over alternative frameworks. For example, Hofstede's (1998) model focuses on the concept of differentiation in national cultures, whereas this study focuses 
on one organisation within the UK only. Peters and Waterman's (1982) observation provides a formula for organizational success. However, the formula represents a 'one size fits all' perspective thus, will not be feasible within different organisational contexts. Schein's iceberg model of culture (1992) comprises three elements of culture that acts as a tool for organisational change but has been criticised as an over simplistic means that scratches the surface of human behaviour in organisations.

It must be highlighted that the Handy model of culture has its limitations like any other theoretical framework. The types of cultures described offer a more simplistic view of a much more complex phenomena in a practical sense where the behaviour aspects are more subtle and perhaps would be harder to visualise from the limited exposure the researcher will have to face within the organisation (Roots 2002). In the literature, Rajapakse's (2012) theory proposed the notion of a transformation in cultural change prior to ERP adoption as a catalyst for organisational success. It is to this researchers' knowledge that this proposal has not been explored by theorists and is an identified gap for consideration. Thus, the researchers identified Handy model of culture as a self-diagnosis tool for culture that can be utilised as a facilitator for adoption success in order to answer the purpose of this study.

\section{Methodology}

Research is not just a matter of belief or assumption but is founded upon a logic of coherent connections and relationships between data with perseverance of fulfilling its purpose of study (Ghauri and Gronhag 2010). The literature review and purpose of this study are appropriate for qualitative primary data methods in a case study design. Qualitative research aims to gain a depth of understanding that is idiographic and socially constructed by each person according to their own personal meaning systems. Qualitative data therefore embraces rather than avoids individual subjectivity in data related to the studied phenomena (Saunders et al. 2012).

Particularly for this research, culture has an array of possible meanings, and thus is construed differently from different individual perspectives (Hill et al. 2012). Therefore, it is essential that employees provide their interpretation of how they perceive culture within Company A to achieve benefits of the research method deployed. As previously mentioned, academia's interpretation of essential success qualities can be seen to be exposed to subjectivity (Shaul and Tauber 2013) as the 'how' and 'what' element over CSFs can be adopted differently within different organisations hence, a variance in research. Although qualitative data contains ambiguity, they possess depth and thickness for thorough explanation (Saunders et al. 2012), particularly when answering this study's interest in change, culture and the impact of ERP adoption.

Collecting the primary data by semi-structured interviews were chosen for this research as it allowed the researchers to capture the key themes for discussion, but allowed the scope of flexibility in unstructured dialogue that grasps the 
interviewees' enthusiasm and relatedness for the topic (Saunders et al. 2012). Consequently, in-depth details of the interviewee's attitudes and emotive experiences could be elicited (Denscombe 2007).

To maximise the validity of individual perception, a diversified selection of participants were selected across different functions and areas of responsibility within the ERP project. This method promotes the diversity of individual perspectives and thus, facilitated the identification of discrepancies within individual results. This diversity in participant selection holds advantage of a strong means of data collection technique due to its certainty of identifying diverse characteristics that, as a result will enable a documentation of any key themes, values to research and scope of uniqueness within results (Patton 2002). Conversely, a selection within the same function or responsibility within the project will risk bias that undermines the validity of findings as applied to the whole organization. We interviewed in total 10 participants, their details are seen in table 1 below. All interviews were audio-recorded in order to provide a rich raw dataset for thematic analysis. All recorded interviews were transcribed in order to capture hard prints of the data; in addition to its usefulness of visualising the thoughts expressed in interview to facilitate interpretation.

Table 1. Participants with Associated Coding and Role Description - Constructed by the Authors

\begin{tabular}{|c|c|l|}
\hline Participants & Coding & \multicolumn{1}{|c|}{ Role } \\
\hline 1 & KeyUser1 & Super user for Function \\
\hline 2 & Delegate1 & $\begin{array}{l}\text { Delegate requirements from project management team to } \\
\text { functions }\end{array}$ \\
\hline 4 & IT1 & $\begin{array}{l}\text { Internal Consultant: to make sure that the blueprint has } \\
\text { been implemented to the group's requirements }\end{array}$ \\
\hline 5 & IT2 & $\begin{array}{l}\text { Internal Consultant: To help with the resource side to } \\
\text { adoption }\end{array}$ \\
\hline 6 & KeyUser2 & $\begin{array}{l}\text { Internal Consultant: to help communicate any } \\
\text { discrepancies between the new system and the old system }\end{array}$ \\
\hline 7 & HR1 & $\begin{array}{l}\text { Huper user for Function } \\
\text { for the job and support when needed }\end{array}$ \\
\hline 8 & Delegate & $\begin{array}{l}\text { Delegate requirements from project management team to } \\
\text { functions }\end{array}$ \\
\hline 9 & HR2 & $\begin{array}{l}\text { Human Resources: make sure the right people are there } \\
\text { for the job and support when needed }\end{array}$ \\
\hline 10 & KeyUser3 & Super user for Function \\
\hline
\end{tabular}

The purpose of analysis is similar to a way of understanding a business; that the manager must appreciate the business processes as internal mechanisms which need to be harnessed, shaped and themed by means of drawing out the unnecessary complexity of data and make key business decisions from a high level that realises strategic vision. Likewise, an analysis' purpose is to transform 
and draw out conclusions from textual data that generates a visual focus from the reduced volume of text, distinguishing signals from noise and an assembled framework for communicating the essence and value to what the data reveals within the undertaken research (Patton 2015).

The researchers used template analysis to interpret the transcripts. Template analysis holds its representation of a need for organising and interpreting data within a thematically structured fashion defined by the researcher (King 2012). The transcribed text was coded as priori- interpreted according to the researchers' existing theoretical knowledge, before being further organised into hierarchical structures (King 2012). Template analysis integrates codes and themes that arise from the researcher's philosophical position rather than a realist and structured approach (Charmaz 1995). This study takes a contextual constructivist outlook whereby the person's interpretation is seen to be generated from interaction between their experiences and ideas (Peterson 2012).

\section{Findings and Discussion}

\section{Company A Profile}

For anonymity purposes we will be referring to our company as Company A. Company $\mathrm{A}$ is an international manufacturing company with a large presence within the European manufacturing industry. Its reputation for excellent customer service and innovative technologies ensures its survival within the competitive market. However, to sustain competitive advantage, Company A has made a strategic decision to upgrade its ERP platforms in the UK, Italy and Germany with a leading ERP product.

The company appointed a new CEO at the beginning of 2012 and upon his arrival; they have embarked on a cultural change program in order to embed new values across the organisation. However, though the culture change was not intended to coincide with the ERP implementation, it ran parallel with company's ERP journey in that the workforce subscribing to the new values should be more willing to embrace the inevitable change that a new ERP system brings. As such, the cultural benefits have already been recognised.

The purpose of this part of our paper is to provide a development and enrichment of the existing constructs of theoretical underpinnings from research already obtainable and referenced within this study's literature review. Handy's model of culture will provide a framework for the analysis of key themes within the data. The list of key themes and justification for selection will be clarified prior to analysis:

\section{$\underline{\text { Old Culture }}$}

Prior to 2012, Company A were controlled and owned by private equity that had their own ways of working practice and, because of their short term outlook, had decided not to invest in ERP previously. This theme was selected due to its relevancy towards the case study of a cultural change embarked in 
2012 and its relevancy in detecting an impact of a change in culture prior to adoption and ERP success - a proposal marked within the literature and a gap identified for further scrutiny.

\section{$\underline{\text { Risks in ERP Adoption }}$}

This theme derived from literature on failures in ERP adoption as a vulnerable stage to risk and project failure (Kumar et al. 2010). It was important for the researchers to establish the threats and underlying concerns that employees and the organisation as a whole were exposed to.

\section{$\underline{\text { New Culture and ERP Impact }}$}

The choice in theme was due to the cultural change program incorporated at Company A as an effect of improved working practise. As the cultural change initiative ran parallel with Company A's ERP journey, it is hoped that the workforce subscribing to the new values should be more willing to embrace the inevitable change that a new ERP system brings. Thus, as a proposal marked within the literature and a gap identified for further scrutiny, this selected theme will assist in clarifying Company A's new form of identity, what changes have been visualised and whether the reengineering to change in culture was a virtuous move pre ERP adoption.

\section{Old Culture}

It was fundamental for the researchers to understand what the culture and working practises were in Company A before the cultural change initiative was implemented back in 2012. When questioned, the majority of the participants voiced that it was a "siloed" organisation.

Prior to 2012, HR1 had stated that the business was assessed by an external firm where business sites and functions within the UK were fundamentally subcultural: "different sites had their own values and own way of working." This echoes the theory related to Martin's (1992) 'differentationist' perspective; in addition to supporting the research of Hofstede (1998) and Harris and Ogbonna (1999) on organizational subcultures. If Company A had retained this old culture through the ERP adoption stage, it can be argued that stakeholder diversity would deter its act away from the 'groupthink' phenomenon (Hill et al. 2012) but would be subject to communicational failure risks associated with project failure (Kumar et al. 2010).

"There were different cultures in different sites but tensions between sites because they were all competitive" - IT2.

This perception was consistently expressed by participants. KeyUser1 stated that there had been an "awful lot of change and an awful lot of ownership and that's created a bumpy ride in regards to culture." The culture was described 
as a very performance and financially driven company where work ethic was high. However, though employees were working hard, a lot of the work was counterproductive by means of strategies and projects conflicting at an expense of "firefighting and unforeseen problems"- which in turn validates the impracticality of stakeholder diversity in ERP adoption, as the conflict of interests divide ERP teams (Barki and Hartwick 2001, Harrison and Klein 2007). Thus, if Company A had adopted ERP within the old cultural identity, possible conflicts could arise and precipitate ERP failure.

KeyUser2 stated that the company was once owned by private equity and the focus of Company A's objectives derived from its priority to maximise profit. From an extreme viewpoint, Delegatel had expressed the presence of ambiguity within the company where "no defined culture" existed and although sites were running within a centralised function, "how people did their roles" was not cohesive. This highlights the aspect of behavioural thinking as a vulnerable and uncontrolled component in businesses which voids the reliability of CSFs as an example identified within the literature. Delegate1 highlighted that often when mergers and acquisitions took place it meant that individual sites had a mentality of working within traditional ways pre-merger and acquisition. This was seconded by IT2 as a UK lead perceptive, who expressed concern for the lack of integration across sites as a result of tensions:

"There were different cultures in different sites but tensions between sites because they were all competitive".

Applying Handy's model of culture, Company A's previous identity would denote a 'power culture' due to its working practise being judged by financial performance and the 'end result' in order to validate its success as an organisation. This explains the actions described by KeyUserl of "working at different agendas" and working hard in order to reach their financial targets. This foresees that Company A's power source and influencing fonts derive from the central figure; that is the private equity owners of the company who represent the organisations actions in working practise.

However, a 'power culture' suffers disadvantages of employee estrangement; that is a tense and unconnected presence between employees, and in Company A's case, tensions between sites. Thus, the result of conflicting projects and strategies from having a "siloed" culture could be the result of triggering this kind of behaviour. As Company A seemingly ran their operations within a centralised system as described by KeyUser2, it was how these central systems were operated that caused problems. Theory indicates that a 'power culture' features a high-level focus to make decisions against the central source, and so lacks a sense of scope from middle-ground employees in decision making and operations (Handy 1976). Thus, this could also account for the competitiveness and tensions between sites. As a 'power culture' characteristic, the results are means to an end (Handy 1976). Thus, sites will only be content if their results achieve paramount success over their internal competitors and, if this identity was 
maintained during adoption, the project would face risk of absent discussions, forecasting project failure (Kumar et al. 2010).

\section{Risks in ERP Adoption}

From the perspective of Delegate1, the overall time constraints provoked apprehension; in addition to concern for the management team and how the "Zeus" project had been managed: "we have an odd management structure... trying to give the project one route and one focus is tricky". The delegate elaborated this complication, explaining that the project management team comprised of two externals and one internal employee within Company A. Thus, the "project management team have one set of skills and knowledge" with regards to knowing the M3 package, but failed to understand and comprehend the expertise surrounding Company A's business processes and needs. It can be argued from existing literature that top management as an identified CSF (Pishdad and Haider 2013) fails at cushioning the risk of differing interests of ERP package and business requirements (Aloini et al. 2012). Therefore, Company A faces risk of failure from the lack of synergy between IT and organisational strategy as well as an unclear focus of objectives where clarity is infrequently eminent (Kumar et al. 2010).

KeyUser1 agreed with the view that Company A had "struggled with project management through this whole journey". However, even though the management had improved, the participant expressed concern for the project being viewed as a "box ticking exercise" where the quality, the detail and the necessary attention by doing things correctly and successfully could potentially be lost from the time pressures that would typically put Company A in the $90 \%$ of organisations who fail to meet the proposed deadline and budget proposed by management (Chang 2004).

"The skills are lacking in the project management team. Therefore, conflict between managers will naturally ensue and confuse people."- IT2.

Applying Handy's model of culture, the "Zeus" ERP implementation presents as a 'task culture' with attributes deriving from a job or project orientated working practise. However, in relation to perspectives originating from the project: the people, the time and the money resources are limited which, as a disadvantage of a 'task culture', hands control over resources to top management- creating a low morale environment within working teams (Handy 1976).

IT1 expressed concern for employees remaining too optimistic with the system that precedes its risk of "people wanting to put everything in scope". Thus, this contradicts KeyUser1 desires of wanting to impart the necessary attention and detail that is offered by the system. IT1 expressed apprehension for the project "running out of budget and running out of time" as necessity for speed was emphasised: "the proof of the pudding is in the eating". Hence, stakeholders are failing to understand what the Group's intentions are; which in turn compels the projects undertaking of a "box ticking exercise" as feared by 
KeyUser1. IT1 elaborated further: "it was quite difficult to get all of the stakeholders aligned because when you have a lot of stakeholders involved, interests are different" where the diversity of stakeholders in Company A stem a conflict between subordinate interests and ERP initiatives in adoption (Barki and Hartwick 2001) - proposing the already seen alteration in subordinate psychological contracts towards their own individual intents (Handy 1976).

It has already been identified that the array of perspectives, objectives and interests are a highly integrational part in successfully managing an ERP project (Fowler and Gilfillan 2003, Somers et al. 2004). However, if Company A fails to manage the communication of ERP initiatives, stakeholder acceptance will not follow. Thus, the conflict and tension between Group and UK initiative could cost strategic focus- an identified CSF for adoption success (Maclennan and Bell 2014).

When the researchers had queried participants in regards to what should have been done differently, both KeyUser1 and Delegate1 were in agreement that there "should have been cross-functional discussions from the start" and that the "project management do not see the issue with lack of cross-functional discussions". KeyUser1 elaborated further from their experience: "it's like dropping a pebble in a pond, if you drop that pebble; that small change will have a ripple effect and particularly in Finance, it can start to affect a lot of different things. Unless you know someone's dropped that pebble in the pond, you can't understand what those ripples will impact". In theory, this proves difficult for 'task cultures' in large organisations where the availability of organising integrational discussions is hard to implement due to the restricted timeframe and availability from employees (Handy 1976). This potentially explains Company A's failed practise for organising such communicative discussions within teams (Kuruppuarachchi et al. 2002, Kumar et al. 2010). Thus, the possible benefits derived from 'task cultures' are potentially offset by the complexity that Company $\mathrm{A}$ is a large organisation.

IT2 reaffirmed the issue of the project management team where, from the participant's past experience of ERP projects, displayed a fundamental warning sign associated with project failure: "if having those people involved in a project in that room isn't affecting the quality of the business then you've got the wrong people". If resources are limited and not utilised appropriately by management, the 'task culture' tends to shift towards a 'power culture' due to difficulties in gaining control and maintaining stability (Handy 1976).

In summary, Company A incorporating a 'task culture' encompasses its philosophy for change, adaptation, individual freedom and low status differentials. But, as seen, the culture is not always suited to the climate and the technology. If organisations are restricted in resources and control over their work, they will not embrace this culture.

\section{New Culture and ERP Impact}

As noted, Company A had embedded a new 'initiative' in 2012 by means of incorporating a single mission, vision and values strategy across all sites in 
order to break the silos within the organisation. As HR1 described: "our culture is evolving". The participant explained that this driving force was engaging with employees across sites in ways could establish improvements through their working practise. This in application to Handy's model represents movement away from 'power culture' as changes in working practise would stem from the leaders as they are the influencers of power to make decisions. Instead, involving the population of Company $\mathrm{A}$ as a focus for decision making is identified as a 'person culture' whereby Company A's 'MVV initiative' exists to serve the individuals within it (Handy 1976).

"We are reinforcing these values to try and eliminate people's perception... to make sure it's interpreted correctly." - HR1.

Thus, Company A's motive is to provide consensus vision through conveying an 'integrationist' perspective "as the correct way to perceive think and feel in relation to those problems" (Schein 1992: 9). However, even though the hope is for a shared influence of a 'person culture' where clarity and strategic focus should benefit, their purpose of control to "eliminate" perception suggests an exercising of power in leadership that is reminiscent of 'power culture' (Handy 1976).

Contradicting HR1's perspective, other participants expressed suspicion over the new 'initiative' as a means of successfully achieving a complete cultural change. For example IT2- having expressed enthusiasm initially for employees' reaction to the new culture and the demand for change being there, Company A had created an additional competition between sites along the lines of which site could incorporate and apply the new values better. Thus, the initiative of a 'person culture' has potentially been undermined by employees failing to recognise that the power of the organisation is a united and equal philosophy. This competitive outlook was observed when KeyUser2 compared their department in initiating the values in comparison to other functions and sites: "I think my department is much more ahead than anyone else in the UK in terms of safety". Thus, a competitive outlook is clearly visible from their perspective of imbedding values.

Conversely, KeyUser1 recognised this discrepancy in Company A's culture and reflected on Company A's journey through cultural transformation:

"Company A hasn't achieved a cultural change, I think that's to come... we have all forgotten that we all work for the same company. We need to look at what needs to be done for the greater good instead of our own agenda".

Hence, Company A is still dependent on the judgment of power, competition and the lack of scope that cultivates alienation and lack of integration amongst employees, at the expense of a more integrated way of working.

Understanding the impact of a change in culture prior to adoption and ERP success is a recognised need (Rajapakse 2012); although the array of stakeholders queried the likelihood of it having a substantial effect in adoption. Delegate1 did however highlight the new initiative's usefulness in coinciding with the 
ERP project by means of incorporating similar traits of "working towards something that is common". Thus, the strategy is not completely alienated. However as argued, the people are still "wary" of the values which insinuates the full benefits of the cultural change are restricted from being fully realised for a heightened adoption.

IT2 reflected on change and how it typically presents "massive challenges" for everybody, but as far as the new initiative is concerned, the workforce have "grabbed the new values". They highlighted that the values had "allowed for a better and different journey" when starting the ERP project. However, as to whether ERP has impacted the culture to a degree in terms of cultural transformation, they stated "in itself, I don't believe so". However, though the end result post implementation may have no effect on cultural transformation, the participant argues that it is the "process of implementing an ERP system that will break some of those barriers". However, it can be argued that this perspective contradicts the issues raised in the theme of 'risks in adoption' where it was postulated that the task of ERP adoption provoked those communication barriers as a result of the conflicts and tensions.

KeyUser1 had emphasised the short timescales in association with the project whereby the period that Company A had allowed themselves for implementation would be "difficult for a cultural transformation" to occur where their primarily focus would be getting the system in to realise the benefits. However, consistent with this theme, "there has to be a real cultural change" for the implementation to be successful where Company A are "focusing an awful lot on system change" currently at adoption - thus, this imposes the risk of ERP conflicting with the power of Company A's culture (Eaton and Kilby 2015) that, as of yet has not fully transformed.

Alternatively, as expressed by HR1, the workforce has accepted the new 'initiative' that was led at the beginning of 2012. The Company A employee engagement survey compared 2011 against 2014 results where significant benefits and changes have occurred since adopting the new culture. With regards to leadership, $82 \%(63 \% ; 2011)$ of employees either agreed or strongly agreed in: sharing the values, believing that the company was well led; in addition to being sufficiently involved in utilising change. As for communication, 77\% $65 \%$; 2011); a 12\% increase from 2011 shows that communication has improved in respect to senior management aligning employees with the objectives and direction of the company. Therefore, in light of the arguments that Company A have not yet achieved a completely transformed culture, the above results contradict this view.

The risks identified from Company A's adoption stem from the lack of communication, managerial leadership and strategic direction within the planning stages. Thus, if the main managerial competences are not correctly managed and applied in adoption, this project will have possibly a negatively impact on the current state of the organisation's culture as well as will create a conflict of interests between UK and Group requirements which could put the ERP project on risk. 


\section{Conclusion}

A critical review was conducted of the concept of CSFs as a measure in ERP adoption. As highlighted by Shaul and Tauber (2013), a substantial mass of $341 \mathrm{CSF}$ have been identified by researchers that act as a catalyst for successful adoption. However, the concept of CSFs has been subject to criticism due to their lack of validity within an applied context. (Tallon and Kraemer 2000, Kappos and Rivard 2008). Research has identified that the unfeasibility in their application could be accounted for by a lack of exclusivity in CSF selection. Following this observation, researchers identified the effective means of adoption failure and, as a result, this was subject to a cultural and human orientated normality. This pinpointed the impracticality of CSFs as a useful tool for ERP success due to its discrepancy in how CSFs are adopted. This observation was supported by its principle of strategy and its feeble influence over the power of culture (Soh et al. 2000, Eaton and Kilby 2015). Thus, if the ERP change element conflicts with the organisation's cultural identity, failure is precipitated. These considerations formed the second part of the literature review with a focus on organisational culture.

The second part of the critical review analysed the concept of organisational culture in detail and its subjective understanding (Hill et al. 2012). Our research discovered the importance of organisational perceptions where the reality, benefits and limitations of subcultures was distinguished in organisations (Martin 1992, Somers et al. 2004). The impact of culture was explored in association with ERP. By nature, it had been distinguished that ERP systems impose their own logic of a company's strategy, culture and processes (Davenport 1998). As a result, it was identified that the disruptive nature in adoption threatens failure for imposed change (Soh et al. 2000). To address this issue, the research identified Rajapakse's (2012) study of eliminating cultural issues in ERP projects by transforming a change in culture prior to adoption. This was the identified gap for further exploration. From this, a self- diagnosis framework of cultural identity was acknowledged; which in turn could be utilised by managers as a catalyst for success (Handy 1976). With an identified gap acknowledged, this triggered the researchers' next phase of conducting interviews at Company A for further scrutiny.

A qualitative data technique through semi-structured interviews allowed the researchers to capture the key themes for discussion but permitted the scope of flexibility in unstructured dialogue. At times, the questions asked were not relevant due to the detail and specifics of the question where hierarchal positions had to be respected for participants' understanding. Thus, semi-structured interviews held advantage within those instances. The limitation of a restricted timeframe as well as the alteration in human perception was identified. Thus, to establish validity, repetition of the research should be conducted. The researchers identified template analysis as a useful tool in order to draw about the unnecessary complexity of textual dialect into a much more meaningful and relevant understanding. The choice in thematic selection was justified in order to mark any understanding of clarity from the identified literature gap. 
We discussed that Company A has recently experienced a period of significant cultural change and there is no question that this has achieved a noticeable improvement in employee engagement and morale. The ERP adoption involves both UK and Group resources and herein lies a challenge in that the Group tends to be task orientated whereas UK is working at developing a policy of employee empowerment. The interviews clearly demonstrated the importance of culture and how it can be construed as a threat to ERP adoption. In addition, the interviews revealed concerns about resources, project management and departmental integration all of which are challenges to Company A. However, there is clear evidence of a high level of commitment from the delegates and key users and whilst challenges remain, successful adoption can be achieved as long as the company prioritises improvement programmes in the areas of weakness.

It has been identified that the new 'initiative' was due to breaking down those silo barriers from Company A's old identity. From the nature of achieving a cultural change, the researchers have identified the new 'initiative' with a 'person culture' as its motive derived from employee focus and, as evidenced by Company A's employee survey, the cultural change has without doubt enhanced benefits of communication, leadership and a sense of coherency - which on paper would increase Company A's chances of achieving a successful ERP adoption. However, as outlined within the theme of 'risks in adoption', it was evident that such risks have not been omitted in practise. Thus, there is no room for complacency as cultural change is a journey and, as described by participants, a full cultural transformation has not yet been realized. It can be argued that if Company A continues to improve its culture then successful ERP adoption could become a reality rather than an ideal. However, if the risks are not appropriately adhered and managed now - not only will Company A face ERP failure in adoption, but will jeopardise their progress through cultural transformation as a result of adopting their old identity as a 'power culture.'

To summarise, in Company A, the ERP project was seen to resemble a 'task culture' due to its nature deriving from a project orientated focus. Thus, we identified a number of complexities from adoption: limited resources, poor project management structure, failed strategic focus and lack of crosscommunicative discussions. This meant that the benefit of the task culture has been offset by its complications of Company A's climate as a large organisation which suffers vulnerabilities as associated from its old cultural identity questioning whether their cultural transformation has been a virtuous one.

Finally, one of the main limitations to this study is on the basis of adoption success. Due to the restricted timeframe, it is unknown whether Company A was successful, or whether any success was due to a cultural change prior to adoption. In order to validate this claim, it is important that researchers not only capture the cultural element through the process of adoption, but also explore postadoption in order to justify how the cultural change element within organisations has an effect on adoption and whether this increment has enabled a successful adoption and to what extent. 


\section{References}

Aloini D, Dulmin R, Mininno V (2012) Modelling and assessing ERP project risks: A Petri Net approach. European Journal of Operational Research 220(2): 484-495.

Avison DE, Myers MD (1995) Information systems and anthropology: and anthropological perspective on IT and organizational culture. Information Technology and People 8(3): 43-56.

Awuah GB, Amal M (2011) Impact of globalization: The ability of less developed countries (LDCs) firms to cope with opportunities and challenges. European Business Review 23(1): 120-132.

Barki H, Hartwick J (2001) Interpersonal conflict and its management in information system development. MIS Quarterly 25(2): 195-228.

Beheshti HM (2010) A decision support system for improving performance of inventory management in a supply chain network. International Journal of Productivity and Performance Management 59(5): 452-467.

Boudreau MC (2002) Learning to use ERP technology: a causal model. In System Sciences, Proceedings of the $36^{\text {th }}$ Annual Hawaii International Conference, 6-9. DOI: 10.1109/HICSS.2003.1174611.

Buonanno GP, Faverio P, Pigni F, Ravarini A, Sciuto D, Tagliavini M (2005) Factors affecting ERP system adoption: A comparative analysis between SMEs and large companies. Journal of Enterprise Information Management 18(4): 384-426.

Chang S (2004) ERP life cycle implementation, management and support: Implications for practice and research. In Proceedings of the $37^{\text {th }}$ Hawaii International Conference on System Sciences 1-10.

Charmaz K (1995) Between positivism and postmodernism: Implications for methods. Studies in Symbolic Interaction 17: 43-72.

Chen C, Law C, Yang S (2009) Managing ERP implementation failure: A project management perspective. IEEE Transactions on engineering management 56(1).

Columbus L (2014) Gartner's ERP Market Share Update Shows The Future of Cloud ERP is Now. Retrieved from https://bit.ly/1spwnDI. [Accessed 25 March 2015].

Davenport TH (1998) Putting the enterprise into the enterprise system. Harvard Business Review. 76(4): 121-131.

Davenport TH (2000) Mission Critical: Realizing the Promise of Enterprise Systems. Boston, MA: Harvard Business School Press.

Davison R (2002) Cultural complications of ERP. Communications of the ACM 45(7): 109-111.

Denscombe M (2007) The Good Research Guide: For Small-Scale Social Research Projects $\left(3^{\text {rd }}\right.$ ed). Maidenhead: Open University Press.

Dezdar S, Ainin S (2011) The influence of organizational factors on successful ERP implementation. Management Decision 49(6): 911-926.

Eaton D, Kilby G (2015) Does your organizational culture support your business strategy? The Journal for Quality and Participation 37(4): 4-7.

Fowler A, Gilfillan M (2003) A framework for stakeholder integration in higher education information systems projects. Technology Analysis and Strategic Management 15(4): 467-489.

Françoise O, Bourgault M, Pellerin R (2009) ERP implementation through critical success factors' management. Business Process Management Journal 15(3): 371-394.

Ghauri PN, Gronhaug K (2010) Research Methods in Business Studies (4 ${ }^{\text {th }}$ ed). New York: Financial Times Prentice Hall. 
Handy CB (1976) So you want to change your organisation? Then first identify its culture. Management, Education and Development 7: 67-84.

Harris LC, Ogbonna E (1999) Developing a Market Oriented Culture: A Critical Evaluation. Journal of Management Studies 36(2): 177- 196.

Hill P, Wu XJ, Beadle R, Brown G (2012) Culture and Organisation. Harlow: Pearson Custom Publishing.

Hofstede G (1998) Attitudes, values and organizational culture: Disentangling the concepts. Organization studies 19(3): 477-493.

Kallunki JP, Laitinen EK, Silvola H (2011) Impact of enterprise resource planning systems on management control systems and firm performance. International Journal of Accounting Information Systems 12(1): 20-39.

Kappos A, Rivard S (2008) A three - perspective model of culture, information systems, and their development and use. MIS Quarterly 32(3): 601-634.

King N (2012) Doing template analysis. In: G Symon, C Cassell (eds) Qualitative Organizational Research, 426-450. London: SAGE.

Harrison DA, Klein KJ (2007) On the diversity of diversity: tidy logic, messier realities. Academy of Management Perspectives 21(4): 26-33.

Kumar PD, Clegg BT, Bennett DJ (2010) Managing enterprise resource planning projects. Business Process Management Journal 16(2): 282-296.

Kuruppuarachchi PR, Mandal P, Smith R (2002) IT project implementation strategies for effective changes: a critical review. Logistics Information Management 15(2): 126-137.

Kwahk K (2006) ERP Acceptance: Organizational Change Perspective. In System Sciences, 2006. HICSS '06, Proceedings of the $39^{\text {th }}$ Annual Hawaii International Conference 8: $172 \mathrm{~b}$.

Law CC, Ngai EWT (2007) ERP systems adoption: An exploratory study of the organizational factors and impacts of ERP success. Information and Management 44(4): 418-432.

Maclennan E, Belle J (2014) Factors affecting the organizational adoption of serviceoriented architecture (SOA). Information Systems and E-Business Management 12(1): 71-100.

Martin J (1992) Cultures in Organizations: Three Perspectives. Oxford: Oxford University Press.

Myers MD, Tan FB (2002) Beyond models of national culture in information systems research. Journal of Global Information Management 10(1): 24-32.

Nah FH, Lau LS, Kuang J (2001) Critical factors for successful implementation of enterprise resource systems. Business Process Management Journal 7(3): 285-96.

Patton MQ (2002) Qualitative Research and Evaluation Methods ( $3^{\text {rd }}$ ed). Thousand Oaks, CA: Sage.

Peters T, Waterman R (1982) In Search of Excellence. New York: Harper and Row.

Peterson TE (2012) Constructivist pedagogy and symbolism: Vico, Cassirer, Piaget, Bateson. Educational Philosophy and Theory 44: 878-891.

Patton MQ (2015) Qualitative research and evaluation methods: integrating theory and practise $\left(4^{\text {th }}\right.$ ed). Thousand Oaks, California: SAGE Publications, Inc.

Pishdad A, Haider A (2013) ERP institutionalization: exploring the influential factors. Journal of Enterprise Information Management 26(6): 642-660.

Rabaai A (2009) The Impact of Organizational Culture on ERP Systems Implementation. In: Proceedings of PACIS.

Rajapakse J (2012) Can ERP Adoptions Change Organisational Culture in Developing Countries in Asia? An Empirical Investigation. In Proceeding of the $45^{\text {th }}$ Hawaii International Conference on System Sciences 5093 - 5101. 
Ram J, Corkindale D, Wu M (2013) Implementation critical success factors (CSFs) for ERP: Do they contribute to implementation success and post-implementation performance? International Journal of Production Economic 144(1): 157-174.

Ram J, Corkindale D, Wu M (2014) ERP adoption and the value creation: Examining the contributions of antecedents. Journal of Engineering and Technology Management 33: 113-133.

Rockart JF (1979) Chief executives define their own data needs. Harvard Business Review 57(2): 81-93.

Roots H (2002) Studying the Types of Organisational Culture. Available at: http://www. mtk.ut.ee.

Saunders M, Thornhill A, Lewis P (2012) Research Methods for Business Students (6 $^{\text {th }}$ ed). Harlow, England; New York: Pearson.

Schein EH (1992) Organizational culture and leadership ( $2^{\text {nd }}$ ed). San Francisco: Calif.

Schein EH (1993) how can organizations learn faster? The challenge of entering the green room. Sloan Management Review 34(2): 85.

Shaul L, Tauber D (2013) Critical success factors in enterprise resource planning systems: review of the last decade. ACM Computing Surveys 45(4): 55-39.

Soh C, Kien SS, Tay-Yap J (2000) Enterprise resource planning: cultural fits and misfits: Is ERP a universal solution? Communications of the ACM 43(4): 47-51.

Somers T, Nelson K, Karimi J (2004) Correction to confirmatory factor analysis of the end-user computing satisfaction instrument: Replication within an ERP domain. Decision Sciences 35(1) 145-146.

Tai JCF, Wang K, Chang HL (2014) How Coaligned Stakeholder Support Enhances End User's Perceived ERP Performance? The Pivotal Role of ERP Identity. In System Sciences (HICSS), 2014 47th Hawaii International Conference 4474- 4483.

Tallon PP, Kraemer KL, Gurbaxani V (2000) Executives' Perceptions of the Business Value of Information Technology: A Process-Oriented Approach. Journal of Management Information Systems 16(4): 145-173.

Umble MM (2003) Enterprise resource planning: Implementation procedures universal solution? Communications of the ACM 43(4): 47-51.

Wei CC, Chen CF, Wang MJJ (2005) An AHP-based approach to ERP system selection. International Journal of Production Economics 96(1) 47-62.

Willcocks LP, Lacity MC (1998) An empirical investigation of information technology sourcing practices: lessons from experience. MIS Quarterly 22(3): 363-408. 